\title{
On-Line Social Network Sites and Negative Social Capital, The Influences in Albanian Economy
}

\author{
Doc. Miftar Ramosacaj \\ Head of Mathematic Department "Ismail Qemali"Vlora University, Albania \\ Email:mramosacaj@yahoo.it
}

Prof Assoc Dr. Alba Robert Dumi

Dean of graduated School “Ismail Qemali"Vlora University, Albania

Email:besi.alba@yahoo.com

Msc. Fjona Zeneli

Master School"Ismail Qemali"Vlora University, Albania Economics Department, University of VIore "Ismail Qemali"

fjona_zeneli@yahoo.com

Doi:10.5901/ajis.2014.v3n1p157

\begin{abstract}
In the terminology of political economy made a distinction between quantitative economic policy and structural economic policies. Quantitative policies are policies aimed at controlling short-term economic cycles through quantitative interventions: fiscal stimulus (decrease or increase taxes and / or government spending), the increase or decrease of the rate of interest, intervention by monetary policy; in other words, the policy aimed at orienting the economy in one or another direction through management macroeconomic parameters. These are policies which in most cases common concern to economists and state fiscal bureaucracy (such as ministries of finance or central bank), or even ideological opposite orientations politicians express the necessity of one or another kind. These groups often finds in dealing with economic problems dealing with the need for or the effects of this kind: for example, given arguments for the necessity of lowering taxes to businesses in order to encourage investment; need for to stimulate demand through increased public spending; debate on the reduction or increase of VAT or excise or tax rates etc.. Foundation is totally debate revolves around the use of the macroeconomic mechanisms in response to cyclical economic developments. In this paper we want to illustrate the facts that both means of supplying markets exporting and production in those markets. Moreover, there are two international business activities that we are studying in our paper research. The main hypothesis is: "Is there a negative "Social Capital"? The database includes 1000 questionnaire about 50 relevant variables (collected during April, May, and June 2011 in Vlore city). The statistical program SPSS is used for creating, testing econometric models which links economic, social and demographic attributes of Internet users with frequencies of accessing / using of the Internet. The paper aims to reach conclusions for the city of Vlore, Albania, to figures out the chances that youth spend hours in Internet contributing in a negative "Social Capital".
\end{abstract}

Keywords: Internet, Negative Social Capital, "Anti-Modern" Society, Informal Networks of Communication

\section{Introduction}

"Social Capital" seems to be related to the Internet and online social network sites. The evidence suggests that the Internet is used for a wide variety of purposes, such as surfing for information, playing onlinegames. Such SNS benefits are derived from social relationships and have been broadly conceptualized as social capital outcomes of SNS use (Ellison et al., 2007). Beyond identifying benefits, new research explores the factors that lead to improved outcomes for SNS users (Burke et al., 2010; Ellison et al, 2010). Given the pervasive use of social network sites (SNSs), there is a need for a careful assessment of the ways in which users incorporate these tools into their daily lives and obtain benefits from use. The goals of the paper are therefore to review the broad themes from this body of work, and to examine the underlying mechanisms through which social capital benefits are generated. By exposing such mechanisms, we will be better prepared to educate future users about usage strategies, as well as aid designers who are adding social features to many new forms of online media. 
${ }^{1}$ Moreover, a large proportion of people report using the Internet for making important life decisions (Howard, et al., 2002).Internet social networks are a fascinating field of research for students and young people who are interested in online technology and their social impacts, evidenced by earlier works ( Boyd \& Ellison, 2007; Donath, 2007;2. Online social networks are based on web services that allow individuals to:

1. Create a public or semi- public profile based on the web;

2. Articulate a list of other users with whom it shares the same connection;

3. See lists of links to other users with whom they share about (Boyd \& Ellison, 2007);

The first social network was launched in 1997; currently there are hundreds of such networks around the globe, relying on the same spectrum of practices, interests and users (Boyd \& Ellison, 2007). One of the largest social networks for Vlore students is Face book (85\% of them are part of social network Face book and the rest of Linkedln, MySpace etc.) (Ramosaçaj M. Survey 2011).Face book was created by Mark Zuckerberg in February 2004. According to him, "... the idea was for a web that it can identify its users ... so Harvard students" (Moyle, 2004)

Among young people are important links between them to generate benefits in terms of "Social Capital" but also in their psychosocial development. Social Capital is an elastic definition that is used to describe the benefits that each receives from social relations with others (Lin, 1999). Ellison and al. (2007) suggests that frequent use of Facebook network is closely connected with the formation and preservation of Social Capital. In one study he found his own connection between Facebook and measurement of Social Capital as bridges of Social Capital (the benefits from information in a heterogeneous network with weak ties) and Social Capital links (emotional benefits from close links with friends and family).

\subsection{Social Capital and the psychosocial development.}

Online social network sites, because of their focus on relationship formation and maintenance, have been extensively studied through the lens of social capital. Three consistent themes are evident across much of the SNS research:

The types of identity information and information disclosure on SNSs influences usage and outcomes, and research confirms that there are benefits that accompany such information disclosure (Burke et al., 2009; Burket et al., 2010; DiMicco \& Millen, 2007; 2008; Donath \& boyd, 2004; Dwyer et al., 2007; Dwyer et al., 2008; Lampe et al., 2006; 2007; Mazur et al., 2009).

There are distinct forms of social capital benefits associated with SNS use, largely divided into bonding social capital - encompassing various forms of social support from strong ties such as close friends and family; and bridging social capital - encompassing exposure to information and resources from weak ties such as co-workers, classmates, and acquaintances (Ellison et al., 2007; Ellison et al., 2009; Steinfieldt al., 2008; Steinfield et al., 2009).

${ }^{3}$ Moreover, Ellison and al. (2007) found evidence that self-esteem can serve as a moderator in the relationship between the use of online social network and Social Capital. For this, young people with low confidence levels appear to benefit more from the use of Facebook than those with higher levels of self-esteem. The fact that data were collected only at one time did not allow the author to define a link between the use of Facebook time, the level of self-confidence and Social Capital.

This suggests the need for additional research in this area, as maintaining relationships through social networking plays an important role in the psychosocial development. There is no a database in Albania, no one knows how many users are in the Internet and their purpose. According to AIREIT (Albanian Institute of Research and Education in Information Technology), the percentage of Internet users moves around $7-8 \%$ of the population. It is an optimistic number but official reports are very pessimistic at the European level. Costs of service of Internet in Albania are higher than costs in Montenegro and about 50 times more than those in the USA (AIREIT's report).

Albania is distinguished for its adaptation to new technologies as above, it suffices to recall mobile adaptation in Albania, and this technology is spread much faster than in Eastern Europe. Is this trend explaining the growing trend of using social network Facebook?

\footnotetext{
${ }^{1}$ Charles Steinfield, Nicole Ellison, Cliff Lampe, and Jessica Vitak Department of Telecommunication, Information Studies \& Media Michi gan State University

2 Ellison, Steinfield \& Lampe, 2007; Golder, Wilkinson \& Huberman, 2007; Lampe, Ellison \& Steinfield, 2007; Valkenburg, Peter \& Schouter, 2006)

${ }^{3}$ Ellison et al., 2007; Ellison et al., 2009; Steinfieldt al., 2008; Steinfield et al., 2009).Burke et al., 2009; Burket et al., 2010; DiMicco \& Mill en, 2007; 2008; Donath \& boyd, 2004; Dwyer et al., 2007; Dwyer et al2008; Lampe et al., 2006; 2007; Mazur et al., 2009). 


\section{Literature Review and Hypotheses}

The database is the result of a survey conducted in 2011 (1006 questionnaires, Ramosaçaj M.) in Vlore city. Also another extra questionnaire about the use of Face book network is conducted (100 questionnaires, Zeneli F.) Data were obtained for more than 50 variables of interest to this paper, through questionnaires to ensure appropriate database for the article. The questionnaires have collected a set of qualitative and reliable data that are processed with econometric techniques through statistical software to estimate the frequency of Internet use including socio-demographics attributes of Internet users. Is this offline to online pattern implicated in the extent to which users receive social capital benefits from their participation in SNSs? Evidence from recent research suggests that this is, indeed, the case. Much of the prior research examined how frequency and intensity of SNS use was related to bridging and bonding social capital. The econometric models try to find links between various characteristics of users and hours spent on the Internet with the intensity of access / use of the Internet at home. It was found that $53.7 \%$ of students had access to the Internet from home, through fixed equipment installed with wide band wave (broadband access). The econometric models have been tested for heteroscedasticity, normality distribution of errors, multicollinearity to be the best for evaluation of important correlation between users attributes Internet usage and level of Social Capital in the city of Vlore.

\subsection{Data and methodology of study in this paper research}

This article was made created by respecting all the methodological rules. The methodology of this article was based in two parts: Studying the foreign and Albanian literature, bibliographic studies, collecting data from official sources as Albanian Finance Institutions, Bussines in Albania, MOF, and University of Vlora.Resources and from different publications such as magazines. And practicing, which is related with the interviews with leaders and employees of the Public Administration.

To collect the data for this article we made interviews, questionnaires and other researches. In Tirana, Albania no new supply was added to the retail inventory during 2012 as latent demand was previously absorbed by the opening of TEG (Tirana East Gate) at the end of 2011. Demand comprised renewals and sporadic requests from tenants needing new retail space. Source: Colliers International 2009)

We created also a questionnaire, which was composed by 100 questions and $4.8 \%$ of the employees in the central level of the public administration answered. There are two perspectives on the importance of maintaining relationships, especially about populating Vlore students. Firstly, relationships help in generating Social Capital (Lin, 1999) and has important ingredient for adults psychosocial development (Sullivan, 1953). For the youth, social networks like Face book play a vital role in maintaining relationships that would have been lost when the individual moves from isolated network of family relationships. Secondly, there is growing evidence that the use of the Internet in general and social networks like Face book, in particular, related to the individual's sense of self or others measuring psychosocial development, although positive or negative contributions from the use of the Internet in the welfare of the individual are widely debated 4

\subsection{Relationships and Social Capital}

Although Social Capital is an elastic term with a set of definitions in many areas (Adler \& Kwon, 2002, has a (Adler \& Kwon, 2002) general agreement this term when referring to the benefits derived from the individual through social relationships (Lin, 1999). May be perceived negatively when group members not excluded from access to the same benefits to members (Bourdieu \& Wacquant, 1992; Helliwell \& Putnam, 2004) but generally perceived with positive terms (Adler \& Kwon 2002) .

Social Capital is linked with many benefits such as career development (Burt, 1997), organizational success (Nahapiet \& Ghoshal , 1998), and many other social benefits such as better public health and lower crime rates (Adler \& Kwon, 2002) .

It's also related to psychological and physical well being of youth. Morrow (1999) encountered although a lack of

${ }^{4}$ Kraut, Patterson, Lundmark, Kiesler, Mukhopadhyay \& Scherlis, 1998; Kraut, Kiesler, Boneva, Cummings, Helgeson \& Crawford, 2002; Shaw \& Gant, 2002; Valkenburg et al. , 2006). 
consistent measurement methods suggested that young individuals with more Social Capital are more prone to behaviours that lead to better health, academic success and emotional high. ${ }^{5}$
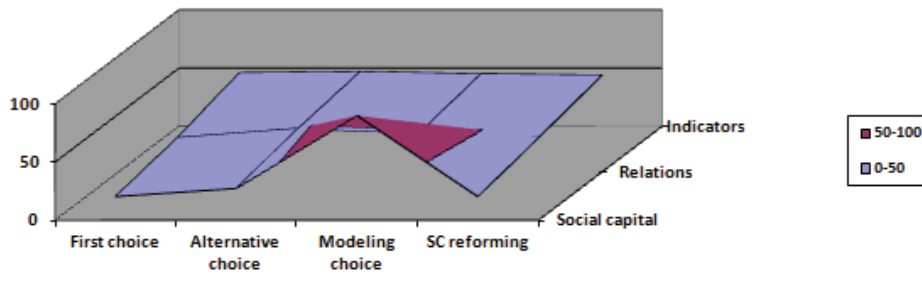

The ability to form and maintain relationships is a prerequisite for the accumulation of Social Capital. For example, Coleman (1988) describes Social Capital as resources collected through relationships with individuals. Lin (1999) extended the notion of emphasizing the importance of developing a social network by taking into account Social Capital. And Wacquant \& Bourdieu (1992) defined as a "sum" of actual or virtual resources that individuals possess the establishment of relationships with others.

\subsection{Forms of Social Capital}

It is important to distinguish between the concept of Social Capital at the individual level and at the community level. For example, Social Capital is seen in the reduction of community participation in social activities among individuals. On the other hand, the greater the Social Capital, the greater the involvement in the community and the greater is the mobility for joint action. At an individual, Social Capital allows individuals to capitalize on their connections with others to obtain information or support benefits.

One must distinguish between two types of Social Capital Connector Bridge (Putnam 2000). Social Capital is the connector between two individuals with strong emotional ties and family, as family and friends Capital bridge or "weak links" refers to two individuals who have lost touch but between them can provide more information than emotional support (Granovetter, 1983 ). Williams (2006) included a broader dimension in how individuals see themselves as part of a group that displays a set of norms on disclosure.

\subsection{Psychological well-being and Social Capital}

Different studies have found different forms of Social Capital including strong ties with friends, neighbours which are associated with psychological well-being and satisfaction with life self made ${ }^{6}$

Most of them examine the links between self-confidence, well-being and measuring Social Capital, stressing the importance of family, intimate relationships and close friends (Bishop \& Inderbitzen, 1995; Keefe \& Berndt, 1996). Lacks evidence of possible links between psychological well-being and nature of Social Capital ties bridge (Constant, Sproull, and Kiesler, 1996).

Discuss this link shows how individuals acquire or no confidence when providing advice from foreign Internet.

\section{Using the Internet, the Development of Relations and Psychosocial Well-Being}

In the past decades a number studies is focused on Internet connections and psychological and psychosocial well-being ${ }^{7}$. Kraut and al. (1998) found that the more frequent use of the Internet, the more phenomena surfaced as loneliness, depression and stress. This is because weak ties created through the Internet replace strong family ties and social. In a study of Kraut et al. (2002) found that if examined for a long time Internet use it was not associated with more poor relations or little involvement in violence.

Other researchers concluded in a positive impact of Internet use in connection with social or family relationships or

\footnotetext{
${ }^{5}$ (Bourdieu \& Wacquant, 1992; Helliwell \& Putnam, 2004) (Adler \& Kwon, 2002 ) See the diagram

6 ( Bargh , McKenna , \& Fitzsimons, 2002; Helliwell \& Putnam , 2004)

${ }^{7}$ Kraut et al.,1998; Kraut et al., 2002; McKenna \& Bargh, 2000; Nie, 2001; Shaw \& Gant, 2002; Valkenburg \& Peter, 2007
} 
psychosocial well-being (Bargh \& McKenna , 2004; McKenna \& Bargh , 2000; Shaw \& Gant, 2002). Bargh and McKenna (2004) have attributed this growth of on-line interactions, to replace lost interaction during their stay on-line.

In an experiment Shaw and Gant (2002) found the decline in perceived loneliness, just like increase in support or confidence during talks on- line. Valkenburg et al. (2006) found that the more individuals use social networks, the higher is the frequency of interaction between friends which brings benefits to the individual levels of self-esteem and their perception on life satisfaction.

\subsection{Measurements of Social Capital}

A recent method of the measurement of Social Capital, it is suggested by L.Hjollund and G.T.Svendsen (2000), part of the project Paldam: "Trust, Social Capital and Economic Growth: An International Comparison". Seeing that most previous studies used the methodology of heterogeneity due to its own concept, the authors suggest such their empirical method which is based on theoretical and empirical approaches affiliated with a comparative survey between Western Europe and Eastern Europe. This is to compare the effects on levels of Social Capital of two different political systems, capitalism and communism. The comparison includes cultural differences (norms and values) and changes on levels of corruption (the quality of institutions) in the implementation of the levels of Social Capital.

\subsection{Capital as formal and informal social relationships}

Rose (1999) defined Social Capital as a set of formal and informal social relationships that individuals set to produce the good or for their allocation. His goal was to identify these relationships, communication networks and the interaction between them. He did not conduct econometric analysis of data. He simply reported marginal distributions of responses to various questions of the questionnaire and formulate conclusions from them. Although the methodology used his paper is an interesting point about the informal networks of communication and formal society named "anti-modern" as Russia. The ideal would be to corrected measurement of Social Capital for those countries with a "negative" indicator of their Social Capital.

Another is presented by authors Krishna and Uphoff (1999), who tested positive relationship with Social Capital and development performance. They constructed an index-oriented development in general and alternative hypotheses were tested, then they tested the validity of the measurement made. They constructed an index of Social Capital from 6 variables, three structural and three conjunctives. This index was proved related positively and significantly with oriented development Index. The data were based on 2397 questionnaires filled with questions related to a wide range of those individuals considered as important local activities.

An approach more "classic" from the economic concept is that of Whiteley (2000), who introduced a measure of Social Capital as an explanatory variable in an endogenous growth model. Measurement is built from the analysis of three essential ingredients of the World Value Study (1990-93), and by categories which Rose included in sociopsychological approximation. Through the explanatory variables (Investment, education), Whiteley measured the GDP I capital in a choice from 34 countries (1972-92). A problem to be discussed is that the variables economic and Social Capital measurements proceed in time (one of the explanatory variables).

And this would bring coincidence discussion between Social Capital and economic performance. The author was aware of this, so he tested it. His indicators included older (less expanded) variables to measure the level of confidence (1981) in a regression model using economic time series from 1981-92 and obtained the same results. The only point of concern was if this model would br important in cases of unexpected significant changes in levels of Social Capital (revolutions, wars holiday, essential changes of political systems, etc.)

Brehm and Rahn (1997) built a structural model of Social Capital, taking into account the interaction between the three concepts, civil engagement, interpersonal trust and confidence in government. Using data from General Social Survey 1972-1994, they estimated their model as an analysis Partial combining three key factors behind the concept and other variables, all measured individually. They evaluated the model through an analysis of covariance structure using as input a correlation matrix. One of the advantages was that missing data avoid deviations. Results showed that the civil engagement and interpersonal trust are in a significant correlation and bond is stronger the higher the interpersonal trust.

\section{Theory Framework of this Study}

It will be considered the link between access and use of Internet, so that the choice made will be divided as follows: 
N1: Number of students with Internet access from home.

N2: Number of students without home Internet access / use.

N3: Number of students without access to home and without the use of the Internet.

$\mathrm{N}=\mathrm{N} 1+\mathrm{N} 2+\mathrm{N} 3$

It can not be measured directly benefit provided by the Internet because there is no such information. But this will be taken into consideration when the model will be specified.

Starting from here, we determine that:

(1) Internet Access $=f$ [Economic Attributes, Technological, Socio-Demographical]

(2) Internet Usage $=f$ [Economic Attributes, Technological, Socio-Demographical | Access]

\subsection{Specification of variables}

Due to the nature of the data collected from the first questionnaire, we use a model involving qualitative variables. Therefore, the model below is been specified for the frequency of broadband Internet access as follows:

(3) Freq_net $=\boldsymbol{\beta}_{0}+\boldsymbol{\beta}_{1} n r_{-}$mem $+\boldsymbol{\beta}_{2} y_{-}$stud $+\boldsymbol{\beta}_{3}$ monthly_inc $+\boldsymbol{\beta}_{4} p c+\boldsymbol{\beta}_{5}$ mob $+\boldsymbol{\beta}_{6}$ broadband $+\boldsymbol{\beta}_{7}$ freq_pc $\boldsymbol{\beta}_{0}$

freq_net - is a quantitative variable and represents the product determinants of the function of the frequency of access and use Internet. Through it we will conclude on investment trends on Social Capital through hours spent in social activities on-line, on levels of trust and degree of involvement in the community (both measuring capital social).

\subsection{Hypotheses}

- Hypothesis 1: The greater the number of members in family, the less frequent is the access/use of the Internet from home; of course, individuals seek other sources facilities outside the house.

- Hypothesis 2: The more educated the household father, the less is the frequent access/use of the Internet from home, assumed that he uses it in the workplace and it's increased the use of mobile phones with the option for featuring the Internet.

- Hypothesis 3: Navigation in the Internet from a mobile, isn't a luxury good anymore and having a personal computer, increases the frequency of access/use the Internet from home.

\subsection{The econometric models}

$\mathrm{R}^{2}=0.6(4)$ Freq_net $=0.131-0.099 \mathrm{nr}$-mem $-0.007 \mathrm{y}$ _stud -0.029 monthly_inc $+0.124 \mathrm{pc}+0.002 \mathrm{mob}+0.522$ broadband +0.529 freq_pc

Stat.Dev. 0.2400 .0480 .0310 .0130 .0510 .0310 .0660 .046

\section{T-Stat $0.546-2.081-2.283 \quad-2.194 \quad 2.427 \quad 2.096 \quad 7.85111 .397$}

The first model supports the seven hypotheses above. It's a significant model $(F=60,112)$, free of multi-collinearity $\left(\mathrm{VIF}_{\mathrm{i}}<3\right)$ and heteroskedasticity and it gratifies the normality tests (Kolmogorov -Smirnov and Shapiro-Wilk).

The more time spent on Face book, the more incentives are on doing things.

$\mathrm{R}^{2}=0.36$

(5) Incentive_to_do_things $=2.695-0.031$ Hours_FB

Stat.Dev. $0 . \overline{151} 0 . \overline{091}$

T-Stat $17.808-0.342$

This model doesn't support the hypothesis above. There is a negative linkage between the incentives on doing something and the hours spent by students on FB. This shows a significant information ( $F=4.117)$ for the negative "Social Capital" that the chosen social network FB produces among the students.

There is not significant information about this. The graphs below (Source: Questionnaire Zeneli F.)

\subsection{Performance indicators of study}

- $\quad n r \_m e m$ - is a quantitative demographic variable which represents the size of the family student interviewed in conducted survey.

- $\quad y \_s t u d$ - is a quantitative educational variable which represents the education level of the student's father. 
- monthly_inc - is a quantitative economic variable which represents the monthly incomes level of the student's family.

- $\quad p c$ - is a qualitative variable which represents the student's state of having or not a portable computer at home.

- $\quad m o b$ - is a qualitative variable which represents the student's state of having or not a mobile with Internet access.

- broadband - is a qualitative variable which represents the student's state of having or not a Broadband Internet access at home.

- freq_pc - is a quantitative variable which represents the frequency of accessing the Internet via portable computer.

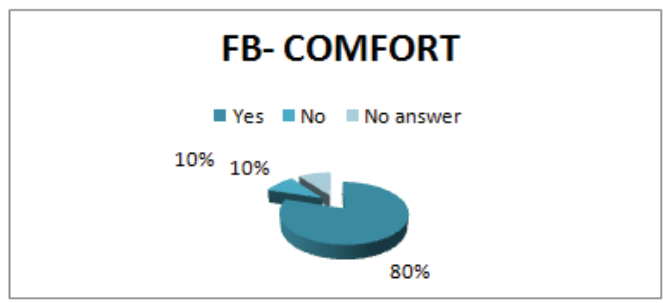

Fig. 1: Question D1: "Do you feel good using your FB account?"

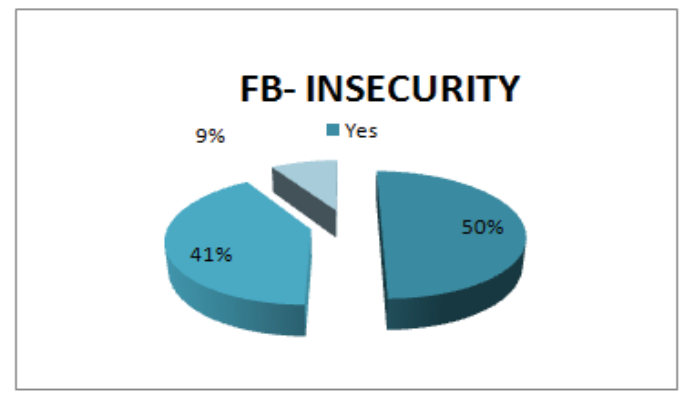

Fig. 2: Question D2: "Do you feel insecurity on your personal Data on FB account?"

Students have no trust on the security of Personal Data on FB account, and they don't feel an increase of their selfesteem (two component of positive "Social Capital"). This Data shows that for students in University of Vlora, having a FB account produces lower self-esteem, no trust and no feeling of the truth.

\section{Conclusions}

The paper managed to formulate an econometric model for frequency evaluations Access / Internet usage by individuals of the sample of 1000 individuals.

The model passed all tests likely to be the right one in consequence theoretical conclusion that derives from it. Interesting for students of the University of Vlora "Ismail Qemali" (individuals who answered the questionnaire), is the fact that they have embraced technology of the Internet, through the opportunitie of access from home, in the workplace, study place or in other public places. It's concluded that this technology is no longer considered a luxury good, the very fact of growing prosperity and improving the ways of Internet access / use (eg. navigation from a mobile, use of free wireless technology in public places, etc.).

Broadband Internet access / usage, shows a scale involvement of individuals in social activities on-line (one of the measures of Social Capital). Previously, based on this can say that the sample area from this viewpoint represents high vitality.

$72 \%$ of survey respondents agreed they are job seekers through the Internet, $75 \%$ use it as the best source of information for their studies, $48 \%$ create personal web site to manage, $84 \%$ are informed on current affairs, $85 \%$ of them 
are part of social network Facebook (and the rest of Linkedln, MySpace).

FB produces a low degree of engagement in networking, a low degree of confidence and trust, in the sample under consideration. These are component of a negative Social Capital.

\section{References}

Barlow, J. P., Birkets, S., Kelly, K., Slouka, M. (1995, August).What are we doing on-line? Harper's, 291, 35-46.

Burt, R. (1997). The contingent value of Social Capital.Administrative Science Quarterly

Coleman, J. S. (1990). Foundations of Social Theory.Cambridge, MA: Harvard University Press.

Dasgupta, P. (1999). Economic progress and the idea of Social Capital.I: Social Capital, A Multifaceted Perspective, eds. Dasgupta, P. og Serageldin, I., Washington D.C.: The World Bank, 1999.

Durlauf, S. (2002). On the Empirics of Social Capital, Economic Journal,112: 459-79. Franzen, A., (2003). Social Capital and the Internet Erickson, B.H. (1996) Culture, class, and connections.American Journal of Sociology 102:217-51.

Flap, H.D. (2002) No man is an island: the research programme of a Social Capital theory. Pp. 29-59 in O. Favereau and E. Lazega (eds), Conventions and Structures. Markets, Networks and Hierarchies.Cheltenham: Edward Elgar.

Flap, H.D. and De Graaf, N.D. (1986) Social Capital and attained occupational status.Netherlands Journal of Sociology 22:145-61.

Fukuyama, F. (1995). Trust: The Social Virtues and the Creation of Prosperity. New York: Free Press.

Krishna, A. and Uphofi N. (1999). Mapping and Measuring Social Capital: A Conceptual and Empirical Study of Collective Action for Conserving and Developing Watersheds in Rajasthan, India.

M. (2000): Social Capital: One or many? - Definition and measurement. Journal of Economic Surveys special issue onpolitical economy.

Ramosaçaj M. \& Zeneli F. (2012), 10th International Conference on Knowledge, Economy and Management,Turkey:"Internet, online social network sites and social capital: an econometric study"

Rose, R., 1999, Getting Things Done in an Antimodern Society: Social Capital Networks in Russia. In Dasgupta Serageldin (1999: 14771).

Snijders, T.A.B. (1999) Prologue to the measurement of Social Capital. La Revue Tocqueville 20:27-44. Communication Sciences.

\section{Appendix}

\section{First Econometric Model; Results and Tests on SPSS}

Variables Entered/Removed

\begin{tabular}{|c|c|c|c|}
\hline Model & Variables Entered & Variables Removed & Method \\
\hline 1 & P10, P4, D2, D5, D3, P11, P8 &. & Enter \\
\hline
\end{tabular}

a. All requested variables entered.

Model Summary

\begin{tabular}{|c|c|c|c|c|}
\hline Model & $\mathrm{R}$ & $\mathrm{R}$ Square & Adjusted R Square & Std. Error of the Estimate \\
\hline 1 &, $673^{\mathrm{a}}$ &, 453 &, 445 &, 638 \\
\hline
\end{tabular}

a. Predictors: (Constant), P10, P4, D2, D5, D3, P11, P8

\section{ANOVA $^{b}$}

\begin{tabular}{|c|c|c|c|c|c|}
\hline Model & Sum of Squares & df & Mean Square & $F$ & Sig. \\
\hline Regression & 171,454 & 7 & 24,493 & 60,112 &, $000^{\mathrm{a}}$ \\
1 Residual & 207,401 & 509 &, 407 & & \\
Total & 378,855 & 516 & & & \\
\hline
\end{tabular}

a. Predictors: (Constant), P10, P4, D2, D5, D3, P11, P8

b. Dependent Variable: P14 


\section{Coefficients $^{\mathrm{a}}$}

\begin{tabular}{|c|c|c|c|c|c|}
\hline \multirow{2}{*}{ Model } & \multicolumn{2}{|c|}{ Unstandardized Coefficients } & \multirow{2}{*}{$\frac{\text { Standardized Coefficients }}{\text { Beta }}$} & \multirow{2}{*}{$\mathrm{t}$} & \multirow{2}{*}{ Sig. } \\
\hline & B & Std. Error & & & \\
\hline \multirow[t]{8}{*}{ (Constant) } & ,131 & 240 & &, 546 &, 585 \\
\hline &,- 029 & 013 &,- 074 & $-2,194$ & ,029 \\
\hline &, 522 & ,066 & ,284 & 7,851 &, 000 \\
\hline & ,124 & ,051 & ,095 & 2,427 & ,016 \\
\hline &, 002 & ,031 &, 003 & 2,096 & ,924 \\
\hline &,- 099 & ,048 &,- 003 & $-2,081$ & ,935 \\
\hline &,- 007 & ,031 &,- 009 & $-2,283$ & ,777 \\
\hline &, 529 &, 046 & ,444 & 11,397 &, 000 \\
\hline
\end{tabular}

a. Dependent Variable: P14

Correlations

\begin{tabular}{|l|c|c|c|c|c|c|c|}
\hline & D2 & D3 & D5 & P11 & P10 & P8 & P4 \\
\hline D2 Pearson Correlation & 1 &,$- 109^{* *}$ &, 007 &,- 045 &,- 034 &,$- 074^{*}$ &,- 007 \\
Sig. (2-tailed) & &, 001 &, 847 &, 195 &, 348 &, 030 &, 831 \\
N & 911 & 882 & 825 & 834 & 744 & 868 & 878 \\
\hline Pearson Correlation &,$- 109^{* *}$ & 1 &, $200^{* *}$ &,$- 100^{* *}$ &,- 062 &,- 052 &, 007 \\
D3 Sig. (2-tailed) &, 001 & &, 000 &, 004 &, 093 &, 123 &, 839 \\
N & 882 & 912 & 826 & 833 & 745 & 867 & 880 \\
\hline Pearson Correlation &, 007 &, $200^{* *}$ & 1 &,$- 179^{* *}$ &,$- 081^{*}$ &,$- 173^{* *}$ &, 016 \\
D5 Sig. (2-tailed) &, 847 &, 000 & &, 000 &, 030 &, 000 &, 635 \\
N & 825 & 826 & 865 & 793 & 709 & 828 & 834 \\
\hline Pearson Correlation &,- 045 &,$- 100^{* *}$ &,$- 179^{* *}$ & 1 &, $309^{* *}$ &, $478^{* *}$ &,- 026 \\
P11 Sig. (2-tailed) &, 195 &, 004 &, 000 & &, 000 &, 000 &, 447 \\
N & 834 & 833 & 793 & 902 & 768 & 880 & 871 \\
\hline Pearson Correlation &,- 034 &,- 062 &,$- 081^{*}$ &, $309^{* *}$ & 1 &, $446^{* *}$ &,- 017 \\
P10 Sig. (2-tailed) &, 348 &, 093 &, 030 &, 000 & &, 000 &, 625 \\
N & 744 & 745 & 709 & 768 & 811 & 800 & 782 \\
\hline
\end{tabular}

\section{Coefficients $^{\mathrm{a}}$}

\begin{tabular}{|c|c|c|c|c|c|c|c|}
\hline \multirow{2}{*}{ Model } & \multicolumn{2}{|c|}{ Unstandardized Coefficients } & Standardized Coefficients & \multirow{2}{*}{$\mathrm{t}$} & \multirow{2}{*}{ Sig. } & \multicolumn{2}{|c|}{ Collinearity Statistics } \\
\hline & B & Std. Error & Beta & & & Tolerance & VIF \\
\hline (Constant) & 2.695 & .151 & & 17.808 & .000 & & \\
\hline Hours_FB & -.031 & .091 & -.036 & -.342 & .733 & 1.000 & 1.000 \\
\hline
\end{tabular}

a. Dependent Variable 
